\title{
Type D Personality, Self-Efficacy, and Medication Adherence in Patients with Heart Failure
}

\author{
Jia-Rong Wu, PhD, RN [Assistant Professor], \\ University of North Carolina at Chapel Hill, School of Nursing, Chapel Hill, NC 27599 \\ Eun Kyeung Song, PhD, RN [Associate Professor], and \\ University of Ulsan, College of Medicine, Department of Nursing, Ulsan, South Korea \\ Debra K. Moser, DNSc, RN, FAAN [Professor] \\ University of Kentucky, College of Nursing, Lexington, KY 40536 \\ Eun Kyeung Song: gracesong77@gmail.com; Debra K. Moser: dmoser@uky.edu
}

\section{Abstract}

Background-Type D personality is a known predictor of non-adherence to prescribed medication regimens among patients with heart failure (HF). Both Type D personality and nonadherence are independent predictors of poor health outcomes among HF patients. Self-efficacy, which is modifiable, is also associated with medication adherence.

Objectives-To determine the relationships among Type D personality, medication selfefficacy, and medication adherence in 84 patients with HF.

\begin{abstract}
Methods-Medication self-efficacy, Type D personality, medication adherence, demographic and clinical data were collected. Hierarchical linear regression and mediation analyses were used.

Results-Type D patients were more likely to have lower medication self-efficacy $(p=.023)$ and poorer medication adherence $(p=.027)$ compared with non-Type D patients. Low medication selfefficacy was associated with poor medication adherence $(p<.001)$. Type $\mathrm{D}$ did not predict $(p=$. 422) medication adherence after entering medication self-efficacy in the model demonstrating that medication self-efficacy was a mediator of the relationship between Type D and medication adherence.
\end{abstract}

Conclusions-Medication self-efficacy mediates the relationship between Type D personality and medication adherence. Developing and applying interventions to enhance medication selfefficacy for Type D patients may help to sever the link between Type D personality and poor outcomes.

(C) 2015 Published by Elsevier Inc.

Address for correspondence: Jia-Rong Wu, PhD, RN, University of North Carolina at Chapel Hill, School of Nursing, 435 Carrington Hall, CB\# 7460, Chapel Hill, NC 27599-7460, Phone 919-966-8057, Fax 919-843-9900, jiarongw@email.unc.edu.

Publisher's Disclaimer: This is a PDF file of an unedited manuscript that has been accepted for publication. As a service to our customers we are providing this early version of the manuscript. The manuscript will undergo copyediting, typesetting, and review of the resulting proof before it is published in its final citable form. Please note that during the production process errors may be discovered which could affect the content, and all legal disclaimers that apply to the journal pertain. 


\section{Keywords}

Type D personality; medication adherence; medication self-efficacy; heart failure

\section{Introduction}

Type D (distressed) personality is a concept used in the field of medical psychology that includes negative affectivity (NA) and social inhibition (SI) personality traits. ${ }^{1,2}$ Type D personality was developed by Dr. Denollet based on clinical and research experience in patients with cardiac disease. Individuals with Type D personality are more likely to have negative emotions (worry, touchiness, sadness) and not to interact or share their thoughts and emotions with others (fear of disapproval).

Patients with Type D personality are more likely to have worse health outcomes. ${ }^{1}$ Previous research has shown that Type D personality is associated with poor quality of life, ${ }^{3-5}$ and higher morbidity, ${ }^{6-9}$ and mortality ${ }^{2,8,10-12}$ among patients with ${ }^{1,2,6,8,10,11,13}$ and without ${ }^{14}$ cardiovascular disease. Patients with heart failure (HF) and Type D personality were more likely to report worse health-related quality of life, ${ }^{3-5}$ more depressive symptoms, ${ }^{5}$ and have a higher cardiac mortality ${ }^{12}$ compared with HF patients without Type D personality.

Many investigators have studied the mechanism(s) linking Type D personality with poor health outcomes. One of the mechanisms potentially linking Type D personality with adverse outcomes is poor self-management skills, including adherence to the recommended medical regimen. For example, patients with obstructive sleep apnea syndrome and Type D personality were more likely to be nonadherent to prescribed respiratory treatment than patients without Type D personality. ${ }^{15,16}$

Medication adherence is a crucial self-care behavior for patients with HF because optimal pharmacological therapy will not benefit patients if they do not take their medications regularly as prescribed. Yet, rates of medication adherence remain suboptimal. ${ }^{17}$ Poor medication adherence is associated with poor health outcomes and leads to high health care costs. ${ }^{18-20}$ To our knowledge, only four investigative groups have examined the relationship between Type $\mathrm{D}$ personality and medication adherence. ${ }^{21-24}$ In these studies, Type D personality was associated with poor medication adherence in patients with myocardial infarction (MI), ${ }^{22}$ acute coronary syndrome (ACS), ${ }^{21}$ asthma, ${ }^{23}$ and HF. ${ }^{24}$

It is not known, however, why patients with Type D personality are more likely to be nonadherent to their prescribed medication. Self-efficacy is frequently found to be associated with health-related behaviors. ${ }^{25}$ Self-efficacy refers to an individual's perception of their ability to perform a specified behavior or set of behaviors in order to produce desired outcomes. ${ }^{26}$ For example, high self-efficacy is associated with better medication adherence. ${ }^{27-33}$ According to Social Cognitive Theory, there is a direct correlation between performance of a behavior and a person's perceived self-efficacy. ${ }^{26}$ Adults with chronic illnesses who have high levels of self-efficacy are more likely to perform self-management behaviors appropriately. ${ }^{33}$ Moreover, there is evidence of a mediating role of self-efficacy. Investigators have demonstrated that self-efficacy mediated the relationship between 
depressive symptoms and medication adherence in 167 African Americans with hypertension, ${ }^{27}$ and between depressive symptoms and adherence to the recommended selfcare regimen in 56 patients with Type 2 diabetes. ${ }^{34}$ Thus, it is plausible that patients with Type D personality may be less likely to adhere to their prescribed medication than their non-Type D counterparts because they have lower medication self-efficacy.

However, it is unknown if medication self-efficacy, a modifiable predictor of medication adherence, mediates the relationship between Type $\mathrm{D}$ personality and medication adherence in patients with HF. Based on empirical findings from the current literature and theoretical support from the Social Cognitive Theory, the purpose of our study was to examine the relationships among Type D personality (and its components [NA and SI]), medication selfefficacy, and medication adherence in patients with HF in order to determine whether medication self-efficacy is a mediator between Type D personality (and its components [NA and $\mathrm{SI}]$ ) and medication adherence in this patient population.

\section{Methods}

\section{Study Design}

This was a secondary analysis of baseline data of a randomized controlled trial (RCT) in patients with HF. The original RCT was to determine whether an educational counseling intervention improved medication adherence and cardiac event-free survival. ${ }^{35}$

Demographic, clinical, and psychological data were collected before randomization by interview, questionnaires, and medical record review.

\section{Sample and Setting}

Detailed eligibility criteria and recruitment methods have been published previously. ${ }^{24,35}$ Briefly, we recruited patients from the outpatient cardiology clinic and inpatient hospitals from the Southern region of the United States. Patients with a confirmed diagnosis of chronic HF who did not change dosage or types of HF medications prescribed by their physician as verified in their medical record were enrolled in the study. We excluded patients with obvious cognitive impairment (as defined by inability to understand the informed consent process or participate in an interview) and any co-existing terminal illness (e.g., end stage renal disease or advanced cancer).

\section{Measurement of Variables}

Independent variable: Type D personality-Type D personality was assessed using the Type D Scale (DS-14), ${ }^{36}$ a 14 -item questionnaire that includes items such as whether patients would describe themselves with phrases such as, "I am a closed person" and "I often feel unhappy." The items were answered on a 5-point Likert scale. Seven items reflect negative affectivity (NA), and seven items reflect social inhibition (SI). Total scores for the NA and SI subscales can range from 0 to 28 to assess these personality traits. People who scored 10 points or more on both the NA and SI subscales were classified as Type D personality. The DS-14 is a reliable and valid instrument that has been used to measure Type D personality in patients with hypertension, ${ }^{36} \mathrm{MI},{ }^{22}$ and HF. $., 12,37$ In this study, Cronbach's alpha was .86 and .82 for the NA and SI subscales, respectively. 
Outcome variable: Medication adherence-Medication adherence was defined as the extent to which the patient's medication-taking behavior corresponded with the medication regimen prescribed by their healthcare provider. ${ }^{38-40}$ The Morisky Medication Adherence Scale [MMAS-4] was used to assess medication adherence. ${ }^{41}$ Patients were asked to answer four items (yes [score $=1$ ], no [score $=0$ ]) assessing whether or not they missed taking any of their medications under four situations over the last month. The scores range from 0 to 4 ; higher scores indicate poorer medication adherence. The MMAS-4 demonstrated relative low, but acceptable internal consistency (Cronbach's $\alpha=.61$ ). It is important to note that our Cronbach's $a$ is the same as demonstrated when the scale was initially used in patients with hypertension. ${ }^{41}$ The MMAS-4 has been used previously to measure medication adherence in patients with HF. ${ }^{42}$

Mediator: Medication self-efficacy-In this study, self-efficacy was defined as medication self-efficacy, which was assessed using the Self-Efficacy for Appropriate Medication Use Scale (SEAMS) ${ }^{28}$ Proponents of Social Cognitive Theory suggest use of a measure that specifically targets self-efficacy in relation to a specific behavior that will better represent the self-efficacy belief. ${ }^{26}$ Patients were asked to answer the stem of "how confident are you that you can take your medicines correctly" for 13 situations (e.g., when you are away from home, when your normal routine gets messed up). Each situation is scored using 1 of the following 3 options: not confident (score $=1$ ), somewhat confident ( score $=2$ ), or very confident ( score $=3$ ). The scores of the 13 items are summed for a total score of 13-39; higher scores indicate higher medication self-efficacy. The SEAMS is a reliable (Cronbach's $a=.89$ ) and valid scale that has been used across different literacy levels in patients with chronic diseases. ${ }^{28}$

Other variables of interest-Age, ${ }^{43}$ gender ${ }^{43,44}$ left ventricular ejection fraction (a measure of ventricular function), ${ }^{45,46}$ and comorbidity (using the Charlson Comorbidity Index), ${ }^{47,48}$ were collected as covariates from medical records or patient interview. These covariates were chosen as they might influence medication adherence. We also collected patients' marital status, length of time with HF diagnosis, body weight and height to calculate body mass index (BMI), New York Heart Association functional classification (NYHA), prescribed medications including angiotensin-converting enzyme inhibitor, and beta-antagonist from patient interview and medication records to characterize patients. BMI was calculated as weight $(\mathrm{kg}) /$ height $\left(\mathrm{m}^{2}\right)$.

\section{Procedure}

Approval to conduct the original RCT was obtained from the Institutional Review Board. The review board at the primary author's current institution approved the secondary data analyses as an exempt protocol. Patient eligibility was confirmed by a trained nurse who then explained study requirements to patients and invited them to participate. After obtaining informed consent, patients' demographic and clinical characteristics were collected by interview and medical record review, and patients completed the DS-14, MMAS-4, and SEAMS. We collected data before randomization to ensure that these data were not influenced by patients' knowledge of the group to which they were randomized. 


\section{Data Analysis}

All data analyses were performed using SPSS (Chicago, IL), version 22.0, 2014; an alpha level of $\leq 0.05$ was used. Data analysis began with a descriptive examination of all variables, including frequency distributions, means, standard deviations, medians, and interquartile ranges, as appropriate to the level of measurement of the variables. Medication adherence was analyzed as a continuous variable. Pearson's correlation was used to examine the relationship between medication adherence and medication self-efficacy. In this study we analyzed Type $\mathrm{D}$ as a categorical variable by dichotomizing patients into Type $\mathrm{D}$ personality or non-Type D personality using the cutpoint of 10 on the NA and SI subscales as has been done in most studies of Type D personality. $3,4,12,49$ Normal distributions for independent and dependent variables were confirmed by histogram, and assessment of skewness and kurtosis $(-2<$ skewness and kurtosis $<+2)$, thereby indicating no violation of the normality assumption of linear regression. In the regression models, we also performed multicollinearity tests to evaluate this assumption of regression. There were no issues with multicollinearity as all variance inflation factors were $<8$.

To test whether medication self-efficacy was a mediator of the relationship between Type D personality and medication adherence, a series of regression analyses were conducted before and after adjusting for demographic (age, gender) and clinical (LVEF and comorbidities) factors. The test for mediation followed the paths outlined by Baron and Kenny. ${ }^{50}$ We tested four regression models to examine the mediator effect as shown in Figure 1.

We also conducted sensitivity analyses by analyzing Type D personality as a continuous variable in the multiple regression and mediation models.

\section{Results}

\section{Patient Characteristics}

Detailed patient characteristics have been published previously. ${ }^{24}$ Briefly, a total of 84 patients with HF were included in this study. More than half of the patients were male. About one quarter of the patients was African Americans. The average length of time of HF diagnosis was $87 \pm 74$ months. The mean LVEF was $38 \% \pm 14.2 \%$. More than half of the patients were married (58\%). The majority of patients were taking ACE inhibitors (70\%) and beta-blocker $(95 \%)$.

\section{Type D personality, Medication Self-efficacy, and Medication Adherence}

The mean (SD) total score of medication self-efficacy was 35.3 (5.0). Patients with Type D personality had a lower score on medication self-efficacy than those without Type D personality (32.2 vs. 36.3, $p=.023)$. Higher scores on medication self-efficacy was correlated with better medication adherence $(\mathrm{r}=.470, p<.001)$. About half $(48 \%)$ of the patients in this study reported that they missed taking some of their medications. Type $\mathrm{D}$ personality was associated with medication adherence in that patients with Type D personality had poorer medication adherence compared with those without Type D personality. ${ }^{24}$ In multiple linear regression, Type D personality was associated with 
medication adherence before and after adjusting for age, gender, LVEF, and comorbidities factors ( $p=.027$ and .05 , respectively).

\section{Mediation Analysis}

In a series of regression analyses, medication self-efficacy was demonstrated to mediate the relationship between Type D personality and medication adherence based on the following sequence of regression analyses. First, in Path A (Table 1, Figure 1), Type D personality independently predicted medication self-efficacy ( $\beta=.356, p=.023)$. Second, in Path B, medication self-efficacy was associated with medication adherence $(\beta=-.47, p<.001)$. Third, in Path C, Type D personality predicted medication adherence $(\beta=-.24, p=.027)$. In the final Path $\mathrm{D}$, Type $\mathrm{D}$ personality was no longer a significant predictor of medication adherence when medication self-efficacy was entered into the model $(\beta=-.084, p=.422)$. After adjusting for age, gender, LVEF, and comorbidity, medication self-efficacy still mediated the relationship between Type $\mathrm{D}$ personality and medication adherence (Table 1).

In addition to Type $\mathrm{D}$ personality, we also performed mediation analysis to examine whether medication self-efficacy mediated the relationship between the Type D components of NA and SI and medication adherence. In Path A, both NA and SI predicted medication selfefficacy ( $p=.001$ and .039 , respectively). In Path B, medication self-efficacy was associated with medication adherence $(p<.001$ ). In Path C, only NA (but not SI) predicted medication adherence $(p=.044)$. In the final Path D, NA was no longer a significant predictor of medication adherence when medication self-efficacy was entered into the model $(p=.417)$. Medication self-efficacy mediated the relationship between NA and medication adherence even after adjusting for age, gender, LVEF, and comorbidity (Table 2).

\section{Sensitivity Analysis}

When Type D personality was analyzed as a continuous variable, we had similar results. Type D personality predicted medication self-efficacy in Path A $(\beta=-.493, p<.001)$. In Path $\mathrm{C}$, Type $\mathrm{D}$ personality was associated with medication adherence before and after adjusting for the same covariates ( $\beta=.276, p=.011$ and $\beta=.267, p=.019$, respectively). In the final Path D, Type D personality was no longer a significant predictor of medication adherence when medication self-efficacy was entered into the model ( $\beta=.058, p=.609$ and $\beta=.074, p$ $=.527$, respectively).

\section{Discussion}

In this study, we explored the associations among Type $\mathrm{D}$ personality, medication selfefficacy, and medication adherence in patients with HF in order to investigate self-efficacy as a potential mechanism linking Type $\mathrm{D}$ personality with poor medication adherence. Selfefficacy is critical for patients with $\mathrm{HF}^{27,31}$ in order to promote better medication adherence. Prior investigators have shown that patients with higher self-efficacy were more adherent to their prescribed medication. ${ }^{27-32}$ We expanded on these findings by demonstrating that medication self-efficacy mediated the relationship between Type $\mathrm{D}$ personality and medication adherence. Type D personality is a distressed personality state that is not likely to change. ${ }^{21}$ Thus, it is helpful to understand that the link between Type D personality and 
poor medication adherence may be uncoupled by improving self-efficacy, which is modifiable.

Our findings about the mediating role of self-efficacy in patients with HF are consistent with those of similar studies. ${ }^{21,27,31,34,51}$ In these studies, self-efficacy mediated the relationship between depressive symptoms or Type D personality and medication adherence among hypertensive patients, ${ }^{27}$ in patients with type 2 diabetes, ${ }^{34}$ and in patients with MI. ${ }^{21}$

Demonstration of mediation by medication self-efficacy of the relationship between Type D and medication adherence provides a valuable opportunity for future intervention work. A few intervention studies had demonstrated the effectiveness of self-efficacy training interventions on health behaviors. ${ }^{52-54}$ Specifically, Lorig and colleagues ${ }^{52}$ tested a selfmanagement, self-efficacy-enhancing intervention which was effective in improving health behaviors, health status, and reduced emergency department visits. Fu and colleagues ${ }^{54}$ found that the Chronic Disease Self-Management Program, which is based on self-efficacy theory, improved amount of aerobic exercise performed, cognitive symptom management, and health status in Chinese patients with chronic diseases. Likewise, Tsay ${ }^{53}$ reported better fluid restriction adherence after self-efficacy training in patients with end-stage renal disease. Our findings, in conjunction with prior researchers' findings, support the importance of self-efficacy for self-care behaviors and provide a potential intervention strategy to improve self-management adherence in patients with chronic diseases.

Self-efficacy is likely a strong mediator of the relationship between Type D personality and medication non-adherence for a number of reasons. Based on social cognitive theory, individuals develop self-efficacy from four sources: enactive attainment (individuals' prior mastery experiences of that behavior), vicarious experience (individuals view others' experiences), verbal persuasion (direct encouragement or discouragement from another person), and physiological state (individuals' perception of their physiological signs of distress: shakes, fatigue, fear). ${ }^{26}$ The aforementioned intervention studies ${ }^{52-54}$ incorporated guided mastery of skills through weekly action planning and feedback of progress, modeling of behaviors, problem-solving strategies, reinterpretation of symptoms, and social persuasions through group support to enhance participant's sense of personal efficacy in their intervention program. However, it is not clear whether one or all of the active components of these self-efficacy enhancing interventions are needed.

This study has limitations that must be considered in interpreting the results. First, the sample size is small, and may produce unstable results in multiple regression models. Thus, these findings need confirmation in a larger sample. Second, although the DS-14 is a reliable measure of Type D personality, the use of potentially artificial cutpoints to dichotomize patients into Type $\mathrm{D}$ and non-Type $\mathrm{D}$ personality groups may result in spurious findings. ${ }^{55,56}$ However, in the sensitivity analysis, when Type D personality was analyzed as a continuous variable, the same results were found, strongly suggesting that the cutpoint is valid. Third, medication adherence was measured only by self-report, a method that is subject to recall bias and social desirability. ${ }^{57}$ Finally, the study is based on cross-sectional data. Therefore, causality cannot be implied. Regardless, the findings from this study 
provide important information related to the nature of the relationships among Type D personality, self-efficacy, and medication adherence in patients with HF.

\section{Conclusion}

Using the Baron and Kenny analytic framework of mediation, we found among HF outpatients, that Type D personality is associated with poor medication adherence, and that this association is explained by medication self-efficacy. If the finding of this study is confirmed in a larger sample, it is crucial to develop and apply interventions to enhance medication self-efficacy for patients who have Type $\mathrm{D}$ personality to improve medication adherence and subsequent outcomes.

\section{Acknowledgments}

source of funding: This study was supported by funding from was supported by the Philips Medical-American Association of Critical Care Nurses Outcomes Grant (Jia-Rong Wu, principal investigator), American Heart Association Great River Affiliate Post-doctoral Fellowship to Jia-Rong Wu, the National Institute Of Nursing Research of the National Institutes of Health under Award Number K23NR014489 (Jia-Rong Wu, principal investigator), and a Center grant to the University of Kentucky, College of Nursing from NIH, NINR, 1P20NR010679 (Debra Moser, principal investigator). Funding agents have no role in study design; in the collection, analysis and interpretation of data; in the writing of the report; and in the decision to submit the article for publication.

\section{References}

1. Denollet J, Sys SU, Stroobant N, Rombouts H, Gillebert TC, Brutsaert DL. Personality as independent predictor of long-term mortality in patients with coronary heart disease. Lancet. Feb 17; 1996 347(8999):417-421. [PubMed: 8618481]

2. Denollet J, Sys SU, Brutsaert DL. Personality and mortality after myocardial infarction. Psychosom Med. Nov-Dec;1995 57(6):582-591. [PubMed: 8600485]

3. Pedersen SS, Herrmann-Lingen C, de Jonge P, Scherer M. Type D personality is a predictor of poor emotional quality of life in primary care heart failure patients independent of depressive symptoms and New York Heart Association functional class. J Behav Med. Feb; 2010 33(1):72-80. [PubMed: 19937107]

4. Schiffer AA, Pedersen SS, Widdershoven JW, Denollet J. Type D personality and depressive symptoms are independent predictors of impaired health status in chronic heart failure. Eur J Heart Fail. Sep; 2008 10(9):922-930. [PubMed: 18942177]

5. Schiffer AA, Pedersen SS, Widdershoven JW, Hendriks EH, Winter JB, Denollet J. The distressed (type D) personality is independently associated with impaired health status and increased depressive symptoms in chronic heart failure. Eur J Cardiovasc Prev Rehabil. Aug; 2005 12(4):341346. [PubMed: 16079641]

6. Denollet J, Brutsaert DL. Personality, disease severity, and the risk of long-term cardiac events in patients with a decreased ejection fraction after myocardial infarction. Circulation. Jan 20; 1998 97(2):167-173. [PubMed: 9445169]

7. Denollet J, Vaes J, Brutsaert DL. Inadequate response to treatment in coronary heart disease : adverse effects of type D personality and younger age on 5-year prognosis and quality of life. Circulation. Aug 8; 2000 102(6):630-635. [PubMed: 10931802]

8. Martens EJ, Mols F, Burg MM, Denollet J. Type D personality predicts clinical events after myocardial infarction, above and beyond disease severity and depression. J Clin Psychiatry. Jun; 2010 71(6):778-783. [PubMed: 20156412]

9. Michal M, Wiltink J, Grande G, Beutel ME, Brahler E. Type D personality is independently associated with major psychosocial stressors and increased health care utilization in the general population. J Affect Disord. Nov; 2011 134(1-3):396-403. [PubMed: 21663973] 
10. Aquarius AE, Smolderen KG, Hamming JF, De Vries J, Vriens PW, Denollet J. Type D personality and mortality in peripheral arterial disease: a pilot study. Arch Surg. Aug; 2009 144(8): 728-733. [PubMed: 19687376]

11. Pedersen SS, van den Broek KC, Erdman RA, Jordaens L, Theuns DA. Pre-implantation implantable cardioverter defibrillator concerns and Type D personality increase the risk of mortality in patients with an implantable cardioverter defibrillator. Europace. Oct; 2010 12(10): 1446-1452. [PubMed: 20719779]

12. Schiffer AA, Smith OR, Pedersen SS, Widdershoven JW, Denollet J. Type D personality and cardiac mortality in patients with chronic heart failure. Int J Cardiol. Jul 23; 2010 142(3):230-235. [PubMed: 19162343]

13. Kupper N, Denollet J. Type D personality as a prognostic factor in heart disease: assessment and mediating mechanisms. J Pers Assess. Dec; 2007 89(3):265-276. [PubMed: 18001227]

14. Mols F, Denollet J. Type D personality in the general population: a systematic review of health status, mechanisms of disease, and work-related problems. Health Qual Life Outcomes. 2010; 8:9. [PubMed: 20096129]

15. Brostrom A, Stromberg A, Martensson J, Ulander M, Harder L, Svanborg E. Association of Type D personality to perceived side effects and adherence in CPAP-treated patients with OSAS. J Sleep Res. Dec; 2007 16(4):439-447. [PubMed: 18036091]

16. Dieltjens M, Vanderveken OM, Van den Bosch D, et al. Impact of type D personality on adherence to oral appliance therapy for sleep-disordered breathing. Sleep Breath. Nov 13.2012

17. Wu JR, Moser DK, Lennie TA, Burkhart PV. Medication adherence in patients who have heart failure: a review of the literature. Nurs Clin North Am. Mar; 2008 43(1):133-153. [PubMed: 18249229]

18. Li H, Morrow-Howell N, Proctor EK. Post-acute home care and hospital readmission of elderly patients with congestive heart failure. Health Soc Work. Nov; 2004 29(4):275-285. [PubMed: 15575455]

19. Chui MA, Deer M, Bennett SJ, et al. Association between adherence to diuretic therapy and health care utilization in patients with heart failure. Pharmacotherapy. Mar; 2003 23(3):326-332. [PubMed: 12627931]

20. Hope CJ, Wu J, Tu W, Young J, Murray MD. Association of medication adherence, knowledge, and skills with emergency department visits by adults 50 years or older with congestive heart failure. Am J Health Syst Pharm. Oct 1; 2004 61(19):2043-2049. [PubMed: 15509127]

21. Molloy GJ, Randall G, Wikman A, Perkins-Porras L, Messerli-Burgy N, Steptoe A. Type D personality, self-efficacy, and medication adherence following an acute coronary syndrome. Psychosom Med. Jan; 2012 74(1):100-106. [PubMed: 22155940]

22. Williams L, O'Connor RC, Grubb N, O'Carroll R. Type D personality predicts poor medication adherence in myocardial infarction patients. Psychol Health. Mar $3.2011: 1-10$.

23. van de Ven MO, Witteman CL, Tiggelman D. Effect of Type D personality on medication adherence in early adolescents with asthma. J Psychosom Res. Dec; 2013 75(6):572-576. [PubMed: 24290048]

24. Wu JR, Moser DK. Type D personality predicts poor medication adherence in patients with heart failure in the USA. International journal of behavioral medicine. Oct; 2014 21(5):833-842. [PubMed: 24198039]

25. Glanz, K.; Rimer, BK.; Viswanath, K. Health Behavior and Health Education: Theory Research and Practice. 4th. San Francisco: Jossey-Bass; 2008.

26. Bandura A. Self-efficacy: Toward a unifying theory of behavioral cange. Psychol Rev. 1977; 84(2):191-215. [PubMed: 847061]

27. Schoenthaler A, Ogedegbe G, Allegrante JP. Self-efficacy mediates the relationship between depressive symptoms and medication adherence among hypertensive African Americans. Health Educ Behav. Feb; 2009 36(1):127-137. [PubMed: 18077654]

28. Risser J, Jacobson TA, Kripalani S. Development and psychometric evaluation of the Self-efficacy for Appropriate Medication Use Scale (SEAMS) in low-literacy patients with chronic disease. J Nurs Meas. 2007; 15(3):203-219. [PubMed: 18232619] 
29. Wolf MS, Davis TC, Osborn CY, Skripkauskas S, Bennett CL, Makoul G. Literacy, self-efficacy, and HIV medication adherence. Patient Educ Couns. Feb; 2007 65(2):253-260. [PubMed: 17118617]

30. Reynolds NR, Testa MA, Marc LG, et al. Factors influencing medication adherence beliefs and self-efficacy in persons naive to antiretroviral therapy: a multicenter, cross-sectional study. AIDS Behav. Jun; 2004 8(2):141-150. [PubMed: 15187476]

31. Johnson MO, Chesney MA, Goldstein RB, et al. Positive provider interactions, adherence selfefficacy, and adherence to antiretroviral medications among HIV-infected adults: A mediation model. Aids Patient Care STDS. Apr; 2006 20(4):258-268. [PubMed: 16623624]

32. Chesney MA, Ickovics JR, Chambers DB, et al. Self-reported adherence to antiretroviral medications among participants in HIV clinical trials: the AACTG adherence instruments. Patient Care Committee \& Adherence Working Group of the Outcomes Committee of the Adult AIDS Clinical Trials Group (AACTG). AIDS Care. Jun; 2000 12(3):255-266. [PubMed: 10928201]

33. Kobau R, DiIorio C. Epilepsy self-management: a comparison of self-efficacy and outcome expectancy for medication adherence and lifestyle behaviors among people with epilepsy. Epilepsy \& behavior : E\&B. Jun; 2003 4(3):217-225.

34. Sacco WP, Wells KJ, Vaughan CA, Friedman A, Perez S, Matthew R. Depression in adults with type 2 diabetes: the role of adherence, body mass index, and self-efficacy. Health Psychol. Nov; 2005 24(6):630-634. [PubMed: 16287410]

35. Wu JR, Corley DJ, Lennie TA, Moser DK. Effect of a medication-taking behavior feedback theory-based intervention on outcomes in patients with heart failure. J Card Fail. Jan; 2012 18(1): 1-9. [PubMed: 22196835]

36. Denollet J. DS14: standard assessment of negative affectivity, social inhibition, and Type D personality. Psychosom Med. Jan-Feb;2005 67(1):89-97. [PubMed: 15673629]

37. Kupper N, Gidron Y, Winter J, Denollet J. Association between type D personality, depression, and oxidative stress in patients with chronic heart failure. Psychosom Med. Nov; 2009 71(9):973980. [PubMed: 19834046]

38. Evangelista LS, Dracup K. A closer look at compliance research in heart failure patients in the last decade. Prog Cardiovasc Nurs. Summer;2000 15(3):97-103. [PubMed: 10951951]

39. Haynes RB, McDonald HP, Garg AX. Helping patients follow prescribed treatment: Clinical applications. Journal of the American Medical Association. Dec 11; 2002 288(22):2880-2883. [PubMed: 12472330]

40. De Geest S, Sabate E. Adherence to long-term therapies: Evidence for action. Eur J Cardiovasc Nurs. 2003; 2(4):323. [PubMed: 14667488]

41. Morisky DE, Green LW, Levine DM. Concurrent and predictive validity of a self-reported measure of medication adherence. Med Care. Jan; 1986 24(1):67-74. [PubMed: 3945130]

42. Farrell K, Shen BJ, Mallon S, Penedo FJ, Antoni MH. Utility of the Millon Behavioral Medicine Diagnostic to predict medication adherence in patients diagnosed with heart failure. J Clin Psychol Med Settings. Mar; 2011 18(1):1-12. [PubMed: 21222020]

43. Monane M, Bohn RL, Gurwitz JH, Glynn RJ, Avorn J. Noncompliance with congestive heart failure therapy in the elderly. Arch Intern Med. Feb 28; 1994 154(4):433-437. [PubMed: 8117176]

44. Roe CM, Motheral BR, Teitelbaum F, Rich MW. Angiotensin-converting enzyme inhibitor compliance and dosing among patients with heart failure. Am Heart J. Nov; 1999 138(5 Pt 1):818825. [PubMed: 10539811]

45. Greenberg BH, Mehra M, Teerlink JR, Ordronneau P, McCollum D, Gilbert EM. COMPARE: comparison of the effects of carvedilol $\mathrm{CR}$ and carvedilol IR on left ventricular ejection fraction in patients with heart failure. Am J Cardiol. Oct 2; 2006 98(7A):53L-59L.

46. Wu JR, Moser DK, Chung ML, Lennie TA. Predictors of medication adherence using a multidimensional adherence model in patients with heart failure. J Card Fail. Sep; 2008 14(7): 603-614. [PubMed: 18722327]

47. Balkrishnan R, Rajagopalan R, Camacho FT, Huston SA, Murray FT, Anderson RT. Predictors of medication adherence and associated health care costs in an older population with type 2 diabetes mellitus: a longitudinal cohort study. Clin Ther. Nov; 2003 25(11):2958-2971. [PubMed: 14693318] 
48. McLane CG, Zyzanski SJ, Flocke SA. Factors associated with medication noncompliance in rural elderly hypertensive patients. Am J Hypertens. Feb; 1995 8(2):206-209. [PubMed: 7755952]

49. Schiffer AA, Denollet J, Widdershoven JW, Hendriks EH, Smith OR. Failure to consult for symptoms of heart failure in patients with a type-D personality. Heart. Jul; 2007 93(7):814-818. [PubMed: 17344329]

50. Baron RM, Kenny DA. The moderator-mediator variable distinction in social psychological research: conceptual, strategic, and statistical considerations. J Pers Soc Psychol. Dec; 1986 51(6): 1173-1182. [PubMed: 3806354]

51. Wolf MS, Davis TC, Osborn CY, Skripkauskas S, Bennett CL, Makoul G. Literacy, self-efficacy, and HIV medication adherence. Patient Educ Couns. Feb; 2007 65(2):253-260. [PubMed: 17118617]

52. Lorig KR, Sobel DS, Ritter PL, Laurent D, Hobbs M. Effect of a self-management program on patients with chronic disease. Eff Clin Pract. Nov-Dec;2001 4(6):256-262. [PubMed: 11769298]

53. Tsay SL. Self-efficacy training for patients with end-stage renal disease. J Adv Nurs. Aug; 2003 43(4):370-375. [PubMed: 12887355]

54. Fu D, Fu H, McGowan P, et al. Implementation and quantitative evaluation of chronic disease selfmanagement programme in Shanghai, China: randomized controlled trial. Bull World Health Organ. 2003; 81(3):174-182. [PubMed: 12764513]

55. de Voogd JN, Wempe JB, Postema K, et al. More evidence that depressive symptoms predict mortality in COPD patients: is type D personality an alternative explanation? Ann Behav Med. Oct; 2009 38(2):86-93. [PubMed: 19513800]

56. Suls J, Bunde J. Anger, anxiety, and depression as risk factors for cardiovascular disease: the problems and implications of overlapping affective dispositions. Psychol Bull. Mar; 2005 131(2): 260-300. [PubMed: 15740422]

57. Wutoh AK, Elekwachi O, Clarke-Tasker V, Daftary M, Powell NJ, Campusano G. Assessment and predictors of antiretroviral adherence in older HIV-infected patients. J Acquir Immune Defic Syndr. Jun 1; 2003 33(Suppl 2):S106-114. [PubMed: 12853859] 


\section{Highlights}

- Medication adherence was worse in Type D patients than in non-Type D patients.

- Type D patients had lower self-efficacy compared with non-Type D patients.

- Self-efficacy mediates the relationship between Type D and medication adherence.

- Interventions to increase medication self-efficacy for Type D patients are needed. 


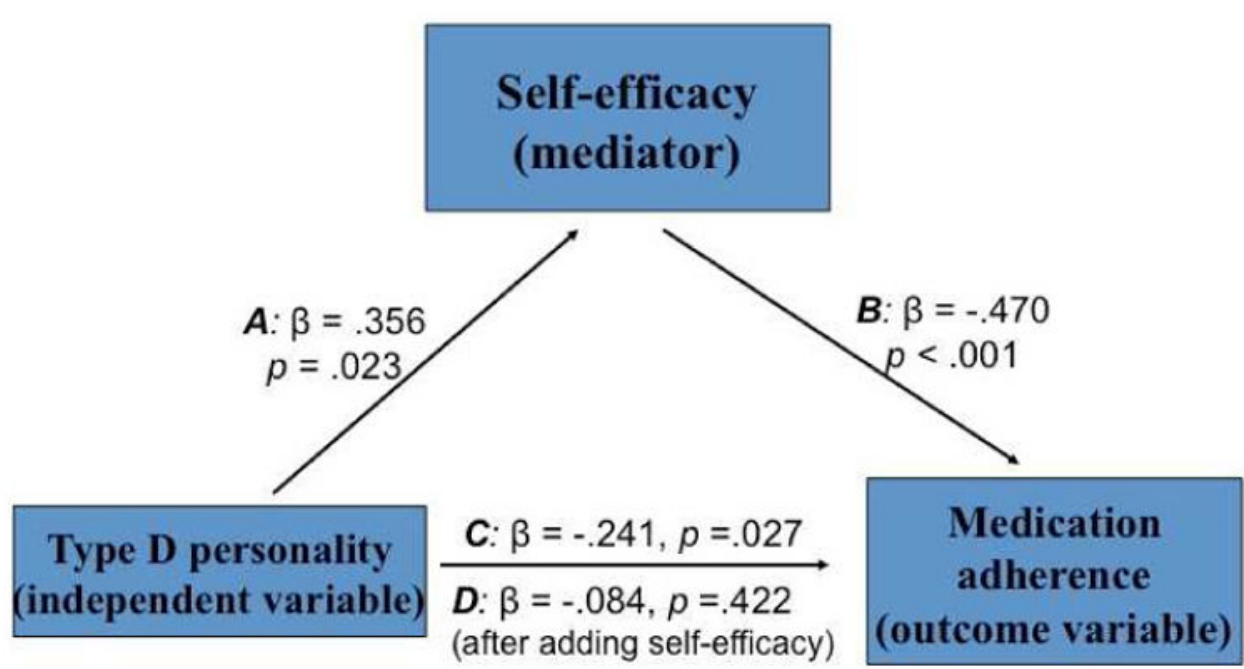

Figure 1. Self-efficacy is a mediator between Type $D$ personality and medication adherence Path A: Test of whether Type D personality is a predictor of medication self-efficacy. Path B: Test of whether medication self-efficacy is a predictor of medication adherence. Path C: Test of whether Type D personality is a predictor of medication adherence. Path D: Test of whether Type D personality and medication self-efficacy together are predictors of medication adherence. 


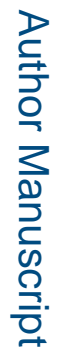

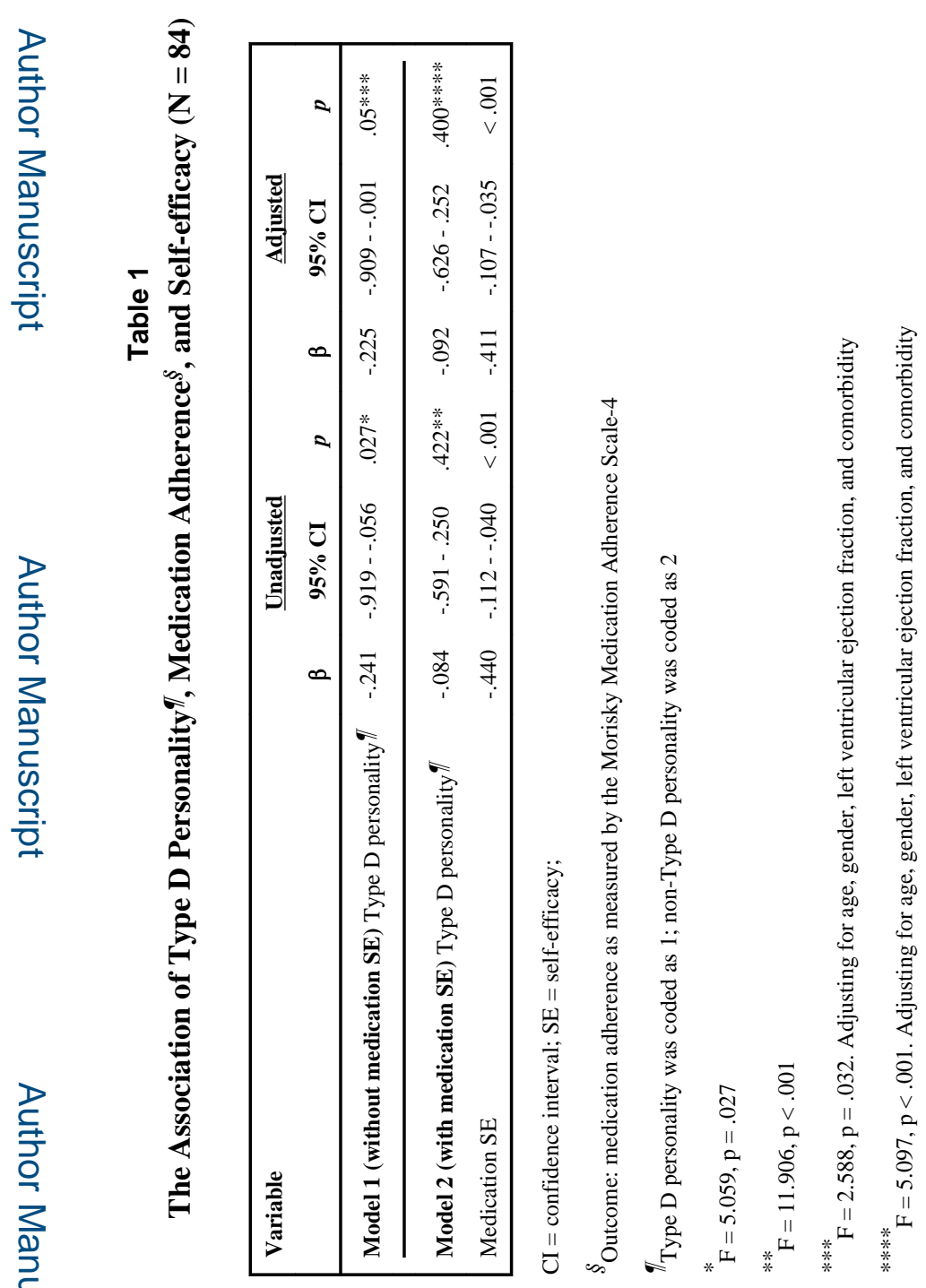

Heart Lung. Author manuscript; available in PMC 2016 July 01. 


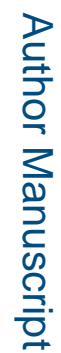

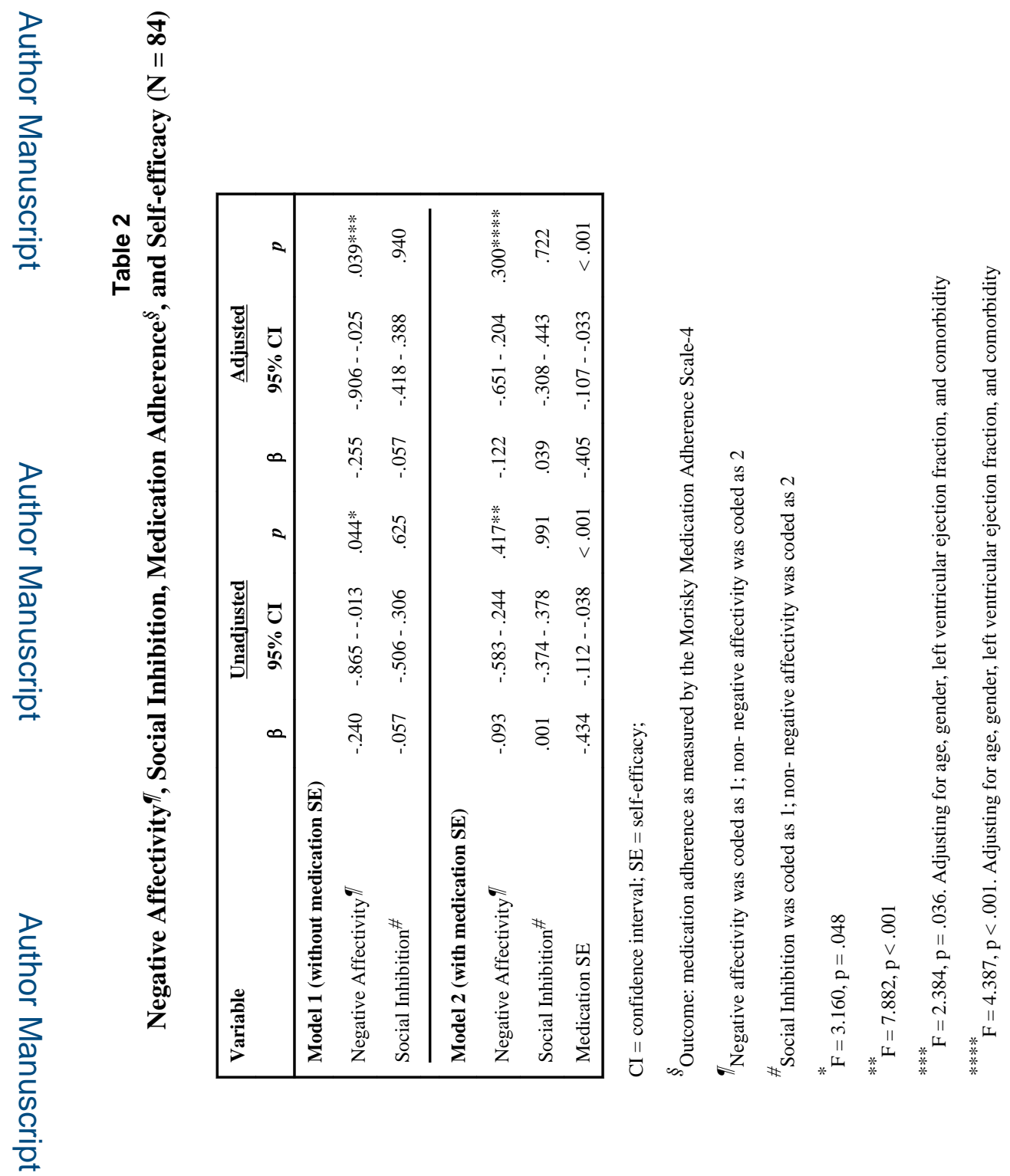

Heart Lung. Author manuscript; available in PMC 2016 July 01. 